\title{
Closing the mineral cycle in dairy farming
}

Clemens Duijnisveld

Product Manager at Lely

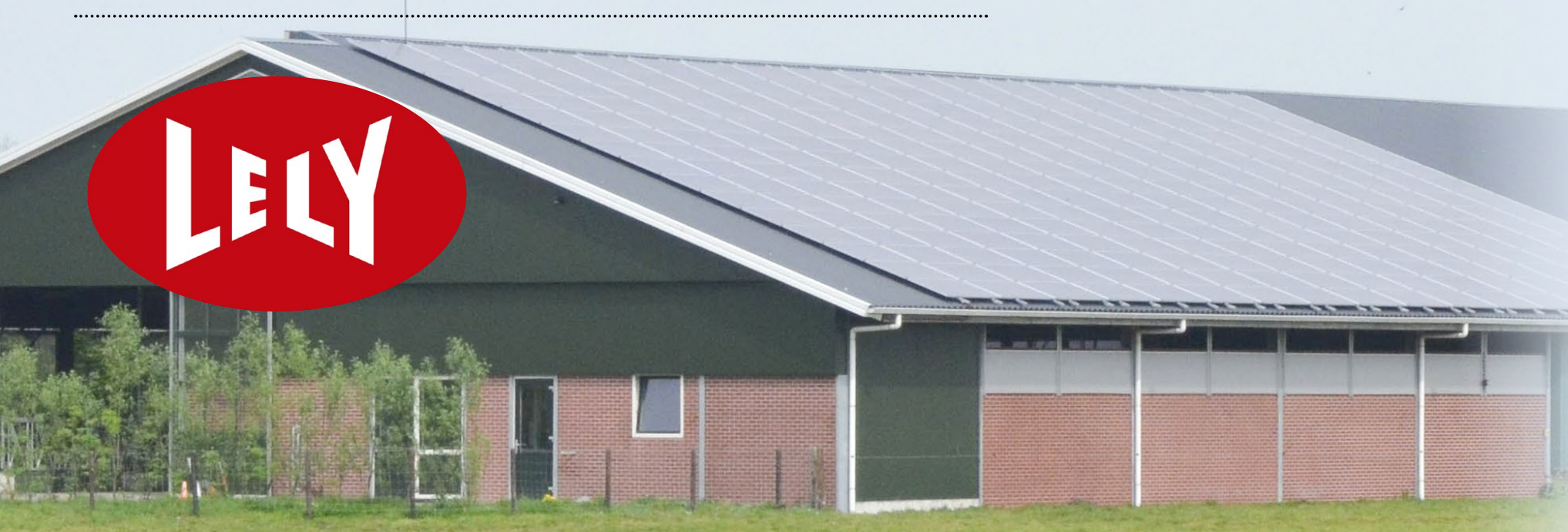

As the world's population will increase by approximately 1.9 billion people towards $2050^{1}$, so will the demand for food. The agricultural sector faces the challenge of increasing its production without the availability of extra land, water and other natural resources.

"Farmers have a very important role for our society because we expect the demand for food to increase by 70 per cent by $2050, "$ Clemens Duijnisveld, Product Manager at Lely.

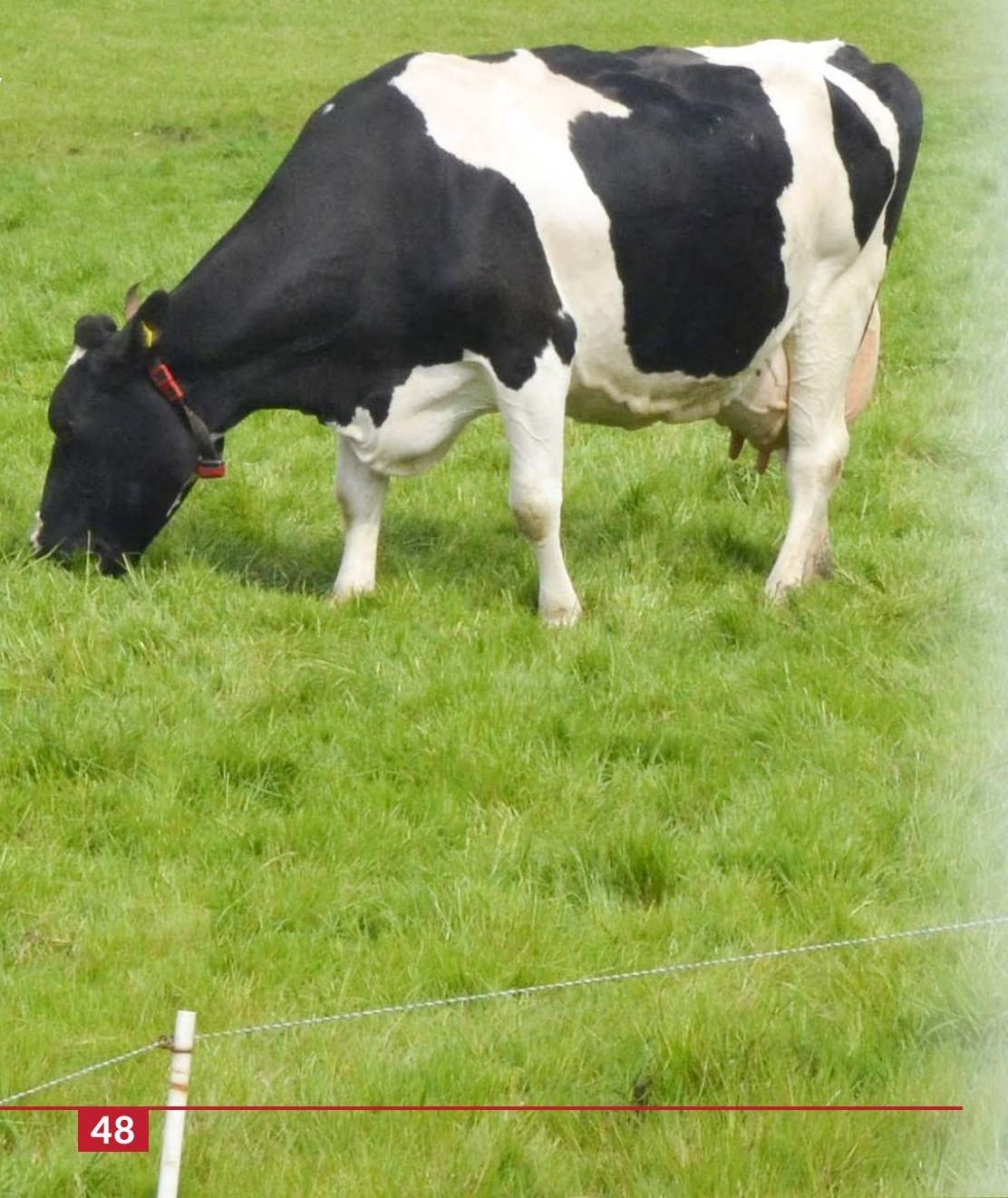

The impact of farming on the environment is also coming under increasing scrutiny, and regulations are becoming stricter. Dairy farmers, for example, need to increase their milk production while improving animal welfare and reducing their ecological footprint. Farmers need to adapt to be able to keep their socalled licence to produce. Adapting to the circular economy is becoming to the circular economy is becoming increasingly important, closing the cycle of nutrients,
emissions.

\section{Dairy farming in perspective}

The European Union (EU) is one of the world's leading producers, consumers, and traders of bovine meat and dairy products. The sector provides employment and contributes to territorial vitality, especially in marginal or vulnerable regions. It provides environmental goods such as EU beef meat and dairy products are regarded as high-quality products that are protected by EU schemes.

Around 3.6 million farms belong to the cattle sector, representing 17 per cent of all EU farms. In merely economic terms, these holdings contribute onethird to the total EU agricultural gross production value, utilise one-third of $E U$ agricultural land and employ one-quarter of the EU agricultural labour force. In the near future, a further increase in milk and bovine meat supply can be expected.

The current challenges of the dairy industry

It is natural for cows to be outside. However, the weather conditions create the need for shelter. More than 90 per cent of the dairy cattle are housed in barns in the main EU dairy-producin countries. In these barns, dairy cattle can move freely, enjoy good quality feed and water and proper cubicles in which the cows lay down to rest. Many of these barns have the ability for the cows to go outside for grazing in case weather conditions are good.

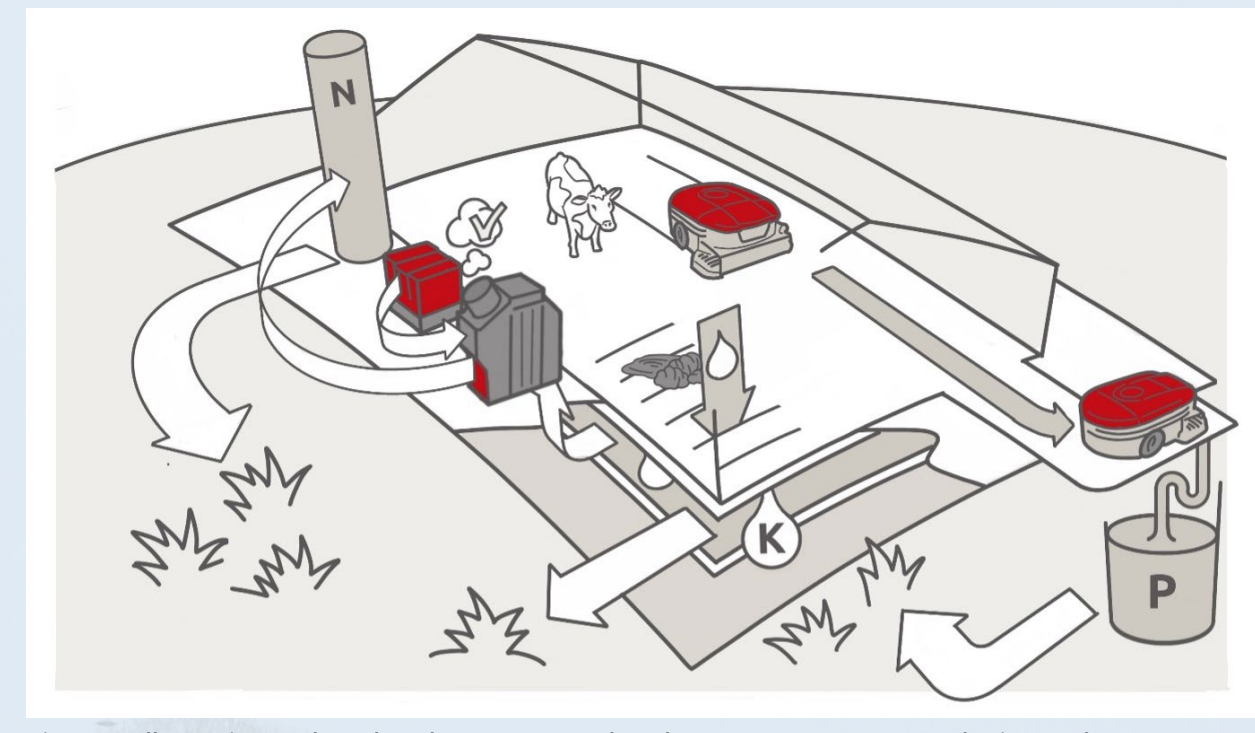

Figure 1: Illustration of the Lely Sphere system. Lely Sphere separates faeces and urine at the source, converts ammonia emissions into
phosphate (P) and potassium (K).

Due to the free movement of the cows in the barn, faeces and urine cannot be prevented from coming together. This leads to the biological forming of ammonia emissions $\left(\mathrm{NH}_{3}\right)$. These emissions could lead to ammonia deposition in natural areas, reducing fauna within these fragile natural areas. This issue is critical in countries such as the Netherlands, Germany, Belgium and North Ireland; influenced by EU regulation, it is expected that more countries will increasingly focus on this aspect.

Animal manure (the combination of faeces and urine) has always been a valuable raw material for farmers to keep soil fertile and provide nutrients for crops. However, as the separation of the various minerals within the manure is challenging, it is nearly impossible to fertilise the needs of the crops in an optimum way. The minerals, which are leaving the farm via milk, meat or import of proct of artifcial fertilsers, stanting the process all over again

Lower emissions and reuse of ammonia

Lely Sphere, is a circular manure-handling system that reduces the undesirable emission of ammonia from the barn by at least 70 per cent, converts the captured ammonia into circular nitrogen fertiliser(s) and separates the urine and faeces. Instead of manure, dairy farmers can now choose from three types of fertilisers for optimal crop growth. The conversion of ammonia into circular nitrogen fertiliser significantly reduces the import of artificial fertiliser, and so improving the mineral loop on the dairy farm.

Reuse of minerals for sustainable crop cultivation The reduction in ammonia emissions achieved by the Lely Sphere system limits the negative impact on the environment by significantly reducing the deposition of ammonia in fragile surrounding nature areas. It also helps make farming operations more circular. Lely Sphere converts ammonia into another nitrogen compound, stored in a silo as liquid, namely ammonium, which can be used as fertiliser. $20 \mathrm{~kg}$ nitrogen per cow per year can be 'harvested' from ammonia emissions. This gives farmers access to a separate stream of nitrogen nutrients that can be used alongside the separated animal urine and faeces. The animal urine contains less mineral nitrogen but is still rich in 1 Source: HYDE (2016) \& UN, WPP (2019).
Practical tests have shown that 10 to 


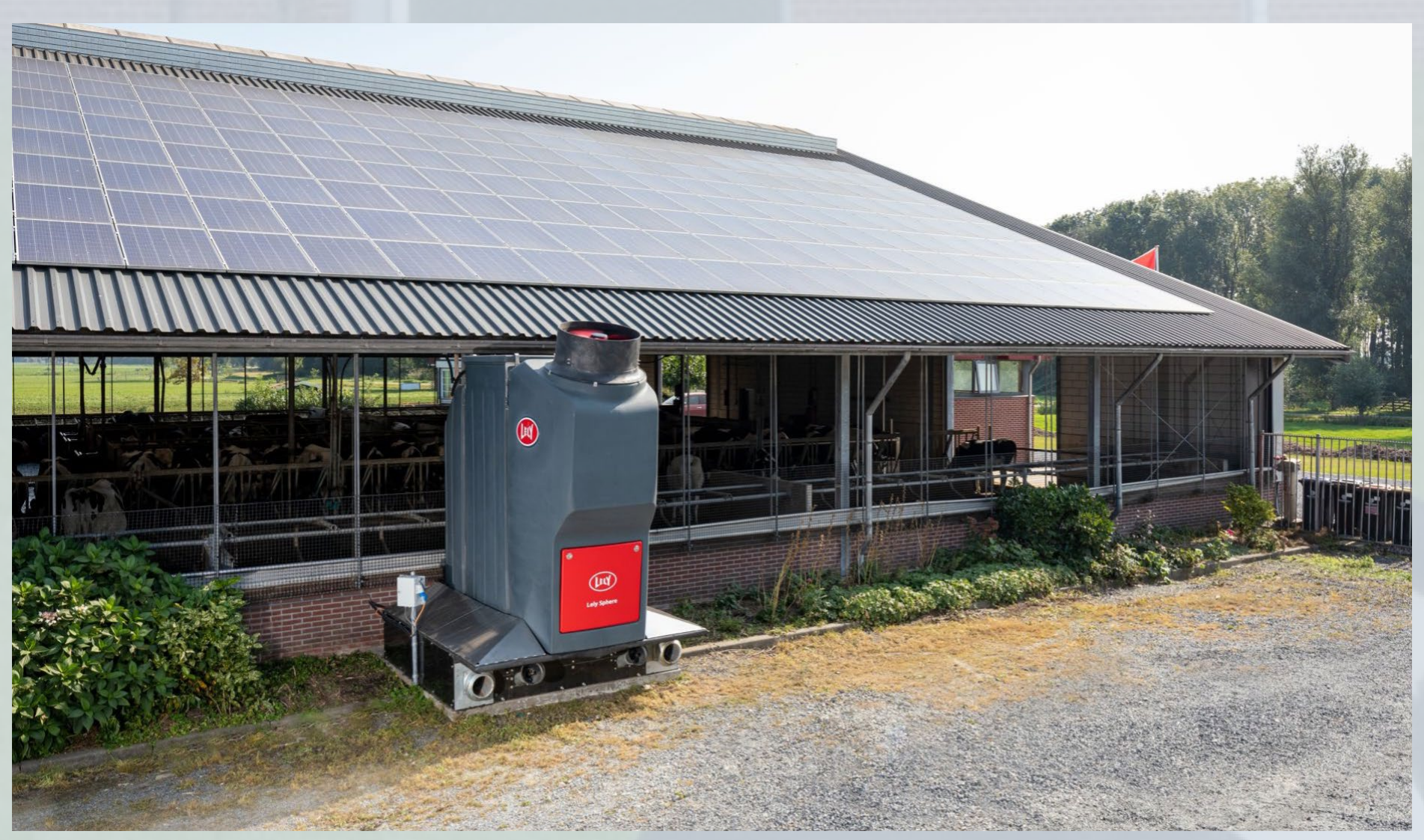
Figure 2: The Lely Sphere $\mathrm{N}$-Capture extracts the manure gases in the cellars and just above the barn floor. The filter package in the $\mathrm{N}$-Capture captures the ammonia and converts it, using water and acid, into circular fertiliser.

other nutrients like potassium, while gases from entering the barn, so the the organic nitrogen and phosphate system improves the climate in the are mainly stored in the faeces. By barn. Space where the cows live and alternating these three streams of the working environment of the farmer nutrients according to the needs of the and the employees become safer, soil, farmers can give their crops what healthier and more pleasant. Air in the they require and improve the quality of barn is extracted via the manure pit, the soil. In addition farmers do not need to buy so much artificial fertiliser.

Safer and healthier for people and animals

Liquid manure storages are anaerobic systems, meaning without oxygen. As organic material in the manure breaks down, the lack of oxygen in the manure liquid promotes hydrogen sulphide, methane and other gas formation. Hydrogen sulphide exposure results in significant health problems. Methane is a fire/explosion hazard when it reaches flammable limits of 5 to $15 \mathrm{per}$ cent by volume. These dangers are present for both humans and animals in the barn.

Lely Sphere's modified slatted floor and ventilation system prevent manure captures the ammonia contained in it.

Lely Sphere is a combination of various manure robot, a unit that extracts air from the manure pit and the barn and converts the ammonia it contal corcular fertiser, and a silo to store circular fertilser. These four eleme circular ferliser, These four elements so the natural ventilation in maintained. The system is ther fore also outside. All gases are extracted from the manure pits below the barn. This This The surface of the modified floor is prevents harmful gases from building up perforated to separate faeces from and reaching a high concentration.

\section{The innovation}

Lely Sphere: a combination of technologies

The results achieved with the Lely Sphere system are due to two effects. The first effect is to limit the formation of ammonia in the barn with technology designed for this purpose. The second manure by means of a unit that extracts Ammonia can form under the floor in air from the manure pit and the barn and the manure pit, but it is extracted by technologies: a modified barn floor, a

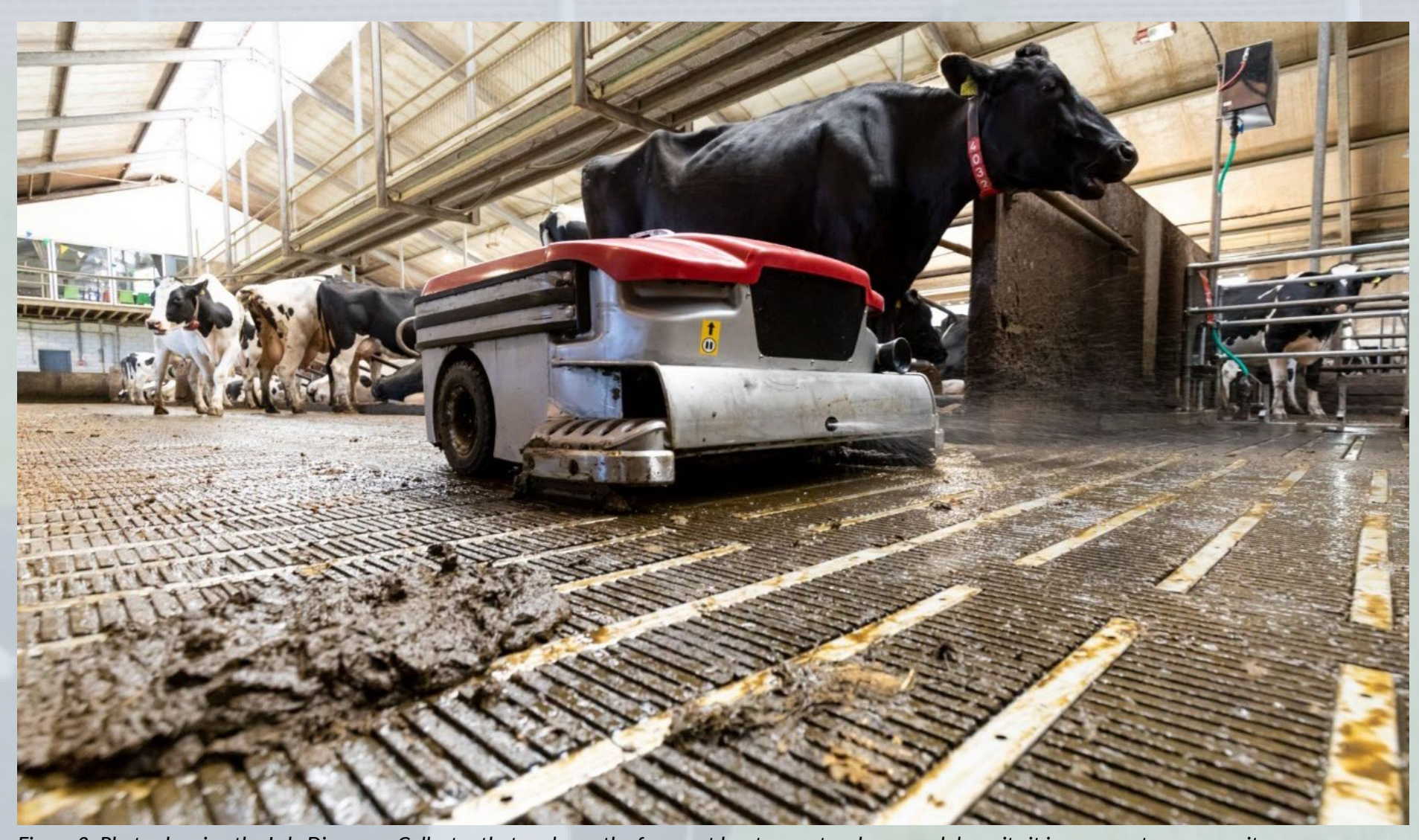

Figure 3: Photo showing the Lely Discovery Collector that sucks up the faeces at least every two hours and deposits it in a separate manure pit.

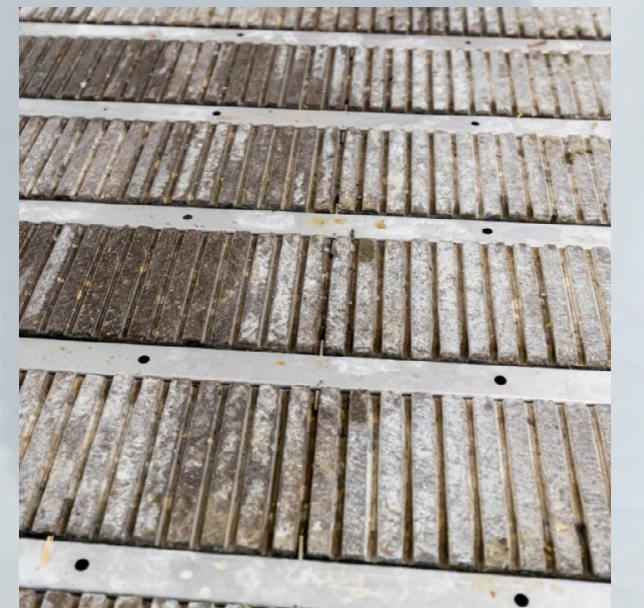

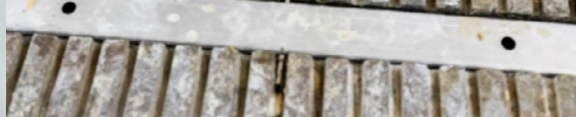
Figure 4: The photo shows strips in the slatted
floor that separate faeces and urine at the source. floor that separate faeces and urine at the source.
The urine flows through the separation strips to the cellar while the faeces remain on top.

the $\mathrm{N}$-Capture, the third element of the system. The $\mathrm{N}$-Capture sucks the air from the pit through a filtering system The ammonia from the extracted air is captured and converted into an air is nitrogen compound (ammonium), which can be used as a substitute for chemical fertiliser.

\section{Benefits in the EU}

Environmental objectives concerning ammonia

Lely Sphere can be beneficial in the EU in various ways. In the first place, the potential reduction in ammonia emissions is important for achieving various environmental objectives. Dairy farming is responsible for a relatively large share of ammonia emissions. In the $\mathrm{EU}$, the agricultural sector is responsible for 94 per cent of total ammonia emissions (Eurostat EU-27, 2010). That represents 3,364 kilotonnes of $\mathrm{NH}_{3}$ per year. Dairy farming is responsible for 47 per cent of this (Eurostat, 2016).

\section{Circular economy}

In the EU, the so-called national NECs (national emissions ceilings) apply to some emission substances like ammonia $\left(\mathrm{NH}_{3}\right)$. This may not be exceeded for each substance for which a ceiling applies. The reuse of ammonia nitrogen as a substitute for artificial fertiliser on dairy farms reflects the ambitions set out in the European Commission's Circular Economy Action Plan. It is also in line with the Farm to Fork strategy to inte the use organic and wastebased fertilisers.

This project concerns the reuse of nitrogen from ammonia. Further processing of manure allows nutrients to be used even more efficiently and specifically in the future for growing crops and improving soil. Dairy farmers recision fertilisation and robotisation technology to refne fertilisation further. Light, autonomous vehiclescan applysmalldoses of fertiser at frequent intervals. For example, Lely is working on the development of Lely Exos (see figure 5), an autonomous vehicle that harvests fresh grass and feeds it to livestock. This vehicle can also apply small doses of liquid fertilisers produced by the Lely Sphere to the grassland instantly after mowing. 


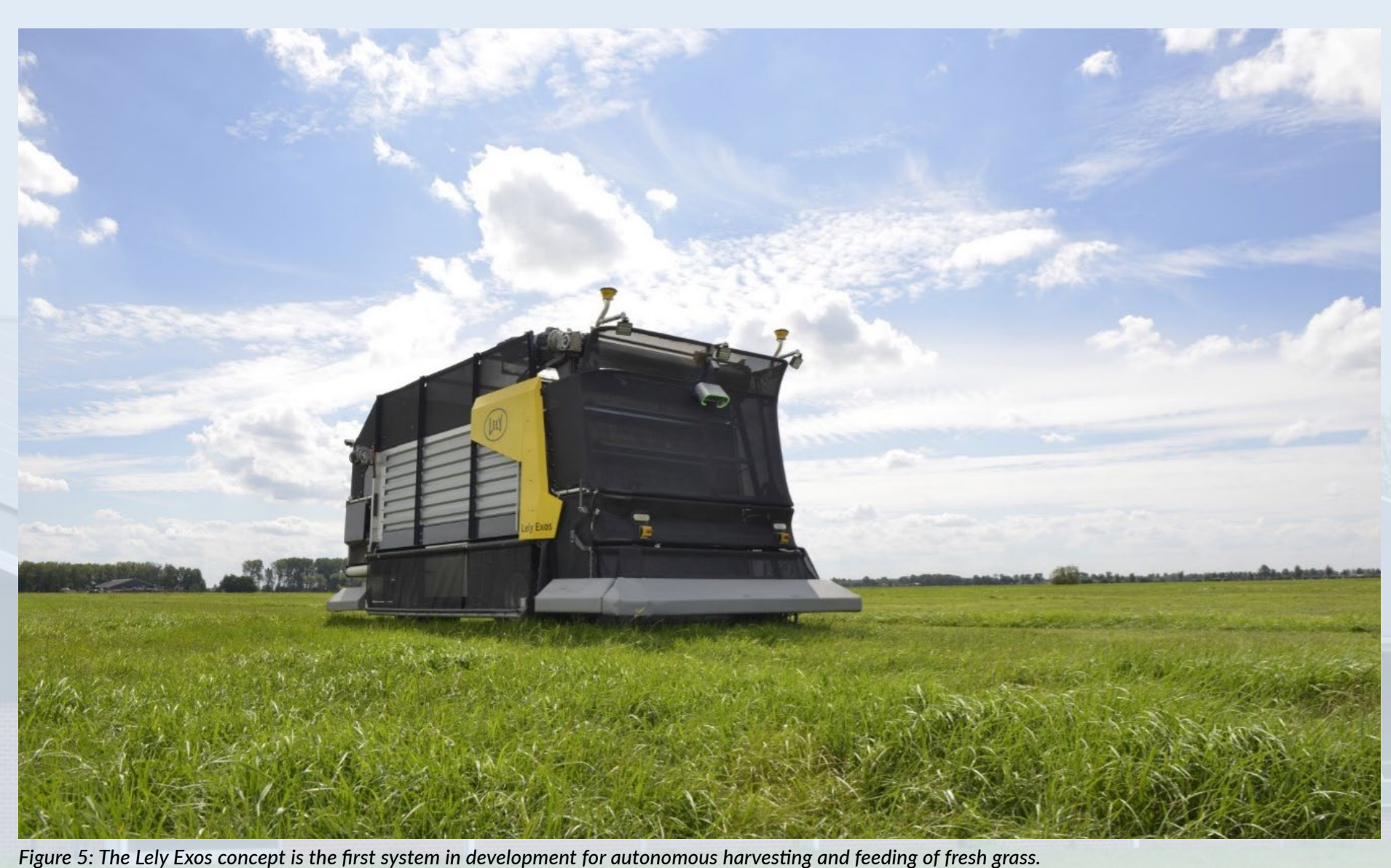

Figure 5: The Lely Exos concept is the first system in development for autonomous harvesting and feeding of fresh grass.

Regional and national regulations In the province Noord Brabant (1 out of 12 provinces) in the Netherlands, we already see future regulations for renovating or newly built dairy farms. Due to be enforced in 2024, these regulations mean that all farms 20 years
or older must be updated to low emission or older must be updated to low emission barns. The expectation is that regulation on the national level will follow the stric regulations of province Noord Brabant.

\section{Results so far}

The Lely Sphere is currently in validation on multiple Lely test farms in the EU. For the RAV certification, the ammonia emission is monitored for an entire year on four dairy farms in the Netherlands with a Lely Sphere system. All measurements needed to receive the official approval are almost finished. On average, measurements show that the in the barn from $13 \mathrm{~kg} \mathrm{NH}_{3} /$ cow/year to $4 \mathrm{~kg} \mathrm{NH}_{3} /$ cow/year, a reduction of 70 per cent. We will focus on scaling up within the Netherlands and start initial installations for gaining approval in other EU countries in the upcoming period.

Partnering with Lely

Lely is an innovative R\&D intensive company that works with various international industry partners such as Datamole, Festo, and knowledge institutions such as Wageningen University. Thand participates in serefore, the company 2020, Eureka (Eurostars, ITEA3) programmes.

\section{About Lely}

Innovating farmers Lely develops, manufactures and the Lely Vector (feeding robot), Juno internationally sells a complete range of (feed pusher) and the Lely Discovery products and services for the agricultural (manure cleaner).

dairy sector, from automated feeding robots.

Lely's vision is a sustainable, profitable focus on innovation, Lely currently is a which are part of the EAFRD, Horizon and enjoyable future in the agricultural sector. To achieve this, innovations in the agricultural sector are of great in the founding of Lely in 1948

The Lely Group headquarters is located Maassluis (NL) and was founded by the brothers Cornelis and Arij van der Lely. Lely shifted its attention to farming and invested in robot technology, which ed to the Lely Astronaut robotic milking system (1992). Through the constant leader in automatic milking, feeding and manure handling.

To ensure optimal cow health and wellbeing, Lely combines animal-friendly and the Lely Vector (feeding robot), Juno

The focus of supporting the farmer and cows remains crucial, especially combined with lowering the farmer's operational cost.

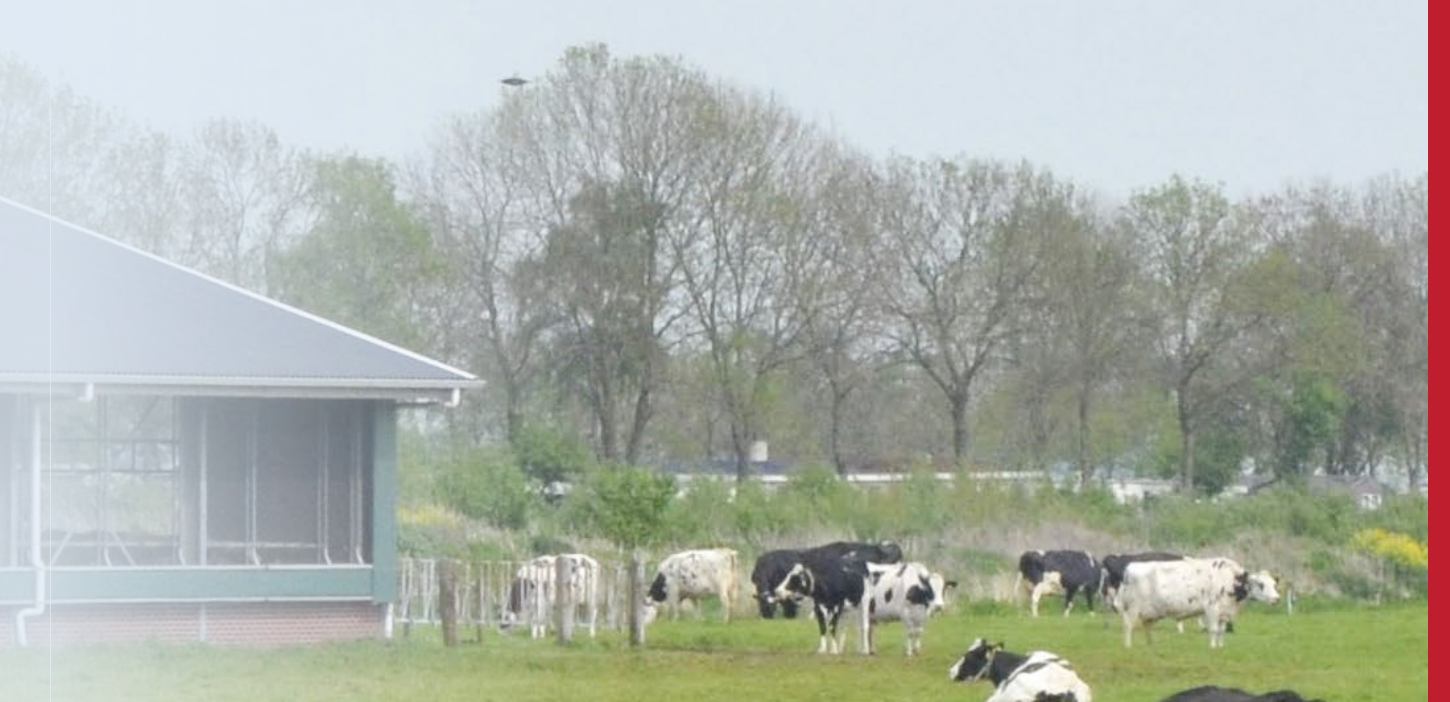

Important figures of the Lely Group (per end 2020)

- $1,600 \mathrm{FTE}$

- 2 production facilities

- 3 R\&D departments with over 250 R\&D engineers

- 1,600 active patents (own patent office)

- Customers in more than 45 different countries

- €615 million sales volume

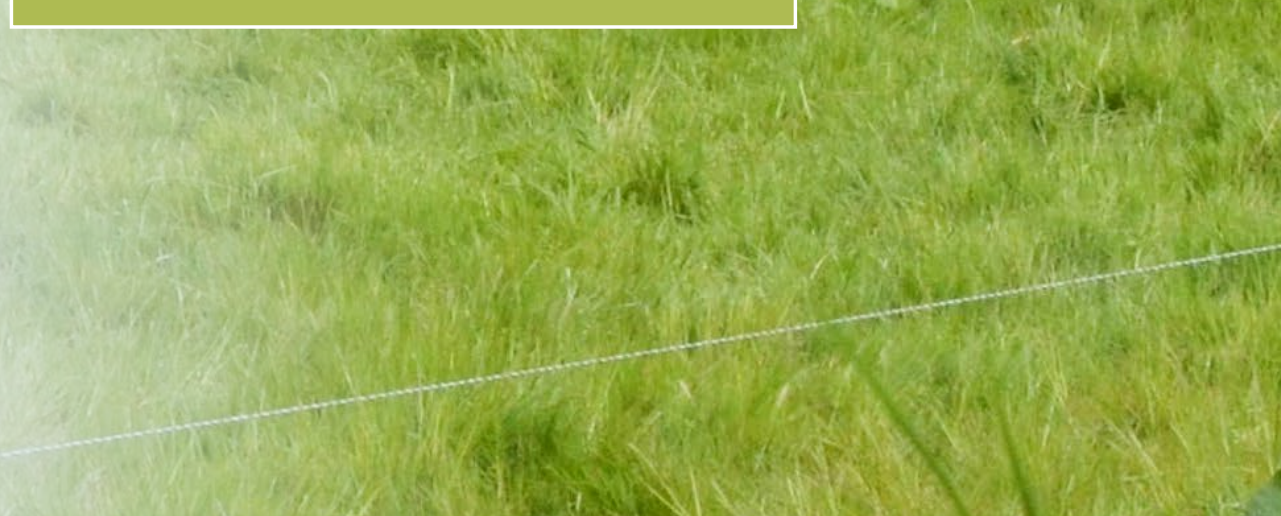

PROJECT SUMMARY

Lely Sphere allows dairy farmers to limit the emissions of ammonia from their barns significantly, use the captured ammonia as Fertiser, and civide the aning the farmer the bility to optimise fertilisation for crops and oils by using the value of emissions.

PROJECT STATUS

The project is currently (Q2 2021) in validation. The Lely Sphere system is on and in one farm in Germany and one farm systems for (he Netherlands (RAV), the commercial rollout will be scaled up. Rollout within other countries will be researched in paralle.

PROJECT PARTNERS

Lely is a Dutch producer of robots and data systems for dairy farming with an international network of franchisers and dealers. The company mainly produces automation and management systems for the dairy industry, including fully automatic
milking robots for feeding, milking and manure handling.

CONTACT DETAILS

Clemens Duijnisveld

(Product Manager Barn \& Manure)

Lely Industries N.V.

Cornelis van der Lelylaan $13147 \mathrm{~PB}$

$+31(0) 881228221$

$\checkmark$ sphere@lely.com

www.lely.com/sphere

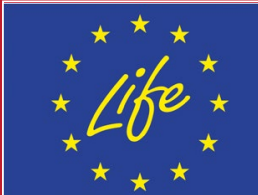

FUNDINC

The LIFE-CMCD project has received funding from .
atFE Programme of the European Union un
. 